УДК 504.75 .05

$10.17213 / 2075-2067-2019-4-62-68$

\title{
ПРИМЕР ВАРИАНТА КОНТРОЛЛИНГА ОБЩЕСТВЕННЫМ ЭКОЛОГИЧЕСКИМ ФОНДОМ СОСТОЯНИЯ АТМОСФЕРНОГО ВОЗДУХА
}

\author{
(C) 2019 г. В. Г. Ларионов ${ }^{*}$ В. В. Ларичкин **, И. А. Сажин ${ }^{* *}$ \\ *Московский государственный технический университет им. М. Э. Баумана \\ **Новосибирский государственный технический университет
}

В статье рассматривается пример контроллинга общественным экологическим фондом состояния атмосферного воздуха в Калининском районе г. Новосибирска. Изложена методика формирования зон загрязнения от комбинации точечных источников ТЭЦ-4. Рассчитаны частные случаи для опасной, низкой и сильной скоростей ветра. Сформированы исходные данные реализации контроллинга состояния атмосферы в данном районе г. Новосибирска общественным экологическим фондом.

Ключевые слова: контроллинг; экологический фонд; загрязняющие вещества; приземная концентрация; область распространения; точечные источники.

The article considers the example of controlling by public environmental fund of the state of atmospheric air in the Kalininsky district of the city of Novosibirsk. The method of forming zones of pollution from a combination of point sources of CHP-4 is described. Special cases are calculated for dangerous, low and strong wind speeds. The initial data on the implementation of controlling the state of the atmosphere in this area of the city of Novosibirsk by the public environmental fund have been formed.

Key words: controlling; environmental fund; pollutants; surface concentration; area of distribution; point sources.

Общественные организации активно участвуют в социально-экономической жизни страны. Благодаря усилиям экологических объединений и фондов удалось добиться конкретных результатов в деле охраны окружающей среды. Экологический фонд «Зеленый стандарт» занимается вопросами минимизации воздействия загрязняющих веществ (ЗВ), связанных с деятельностью предприятий топливно-энергетического комплекса на экологию городов. Ocобое внимание уделяется вопросам загрязнения атмосферного воздуха в промышленных центрах Сибирского федерального округа. В статье рассмотрен один из этапов контроллинга экологическим фондом «Зеленый стандарт» состояния атмосферного воздуха в Калининском районе г. Новосибирска, в котором расположены крупные промышленные предприятия, несколько спальных микрорайонов, торгово-развлекательные центры, дворцы спорта, места массового отдыха. Интегральная экологическая карта города Новосибирска (рис. 1.) показывает, что Калининский район находится в условиях высоко опасной и опасной экологической обстановки. Важным этапом контроллинга состояния атмосферного воздуха является максимально достоверное определение зон повышенной приземной концентрации 3В на основании регламентированных методик.

В качестве объекта экологических измерений выбрана ТЭЦ-4, общий объем выбро- 


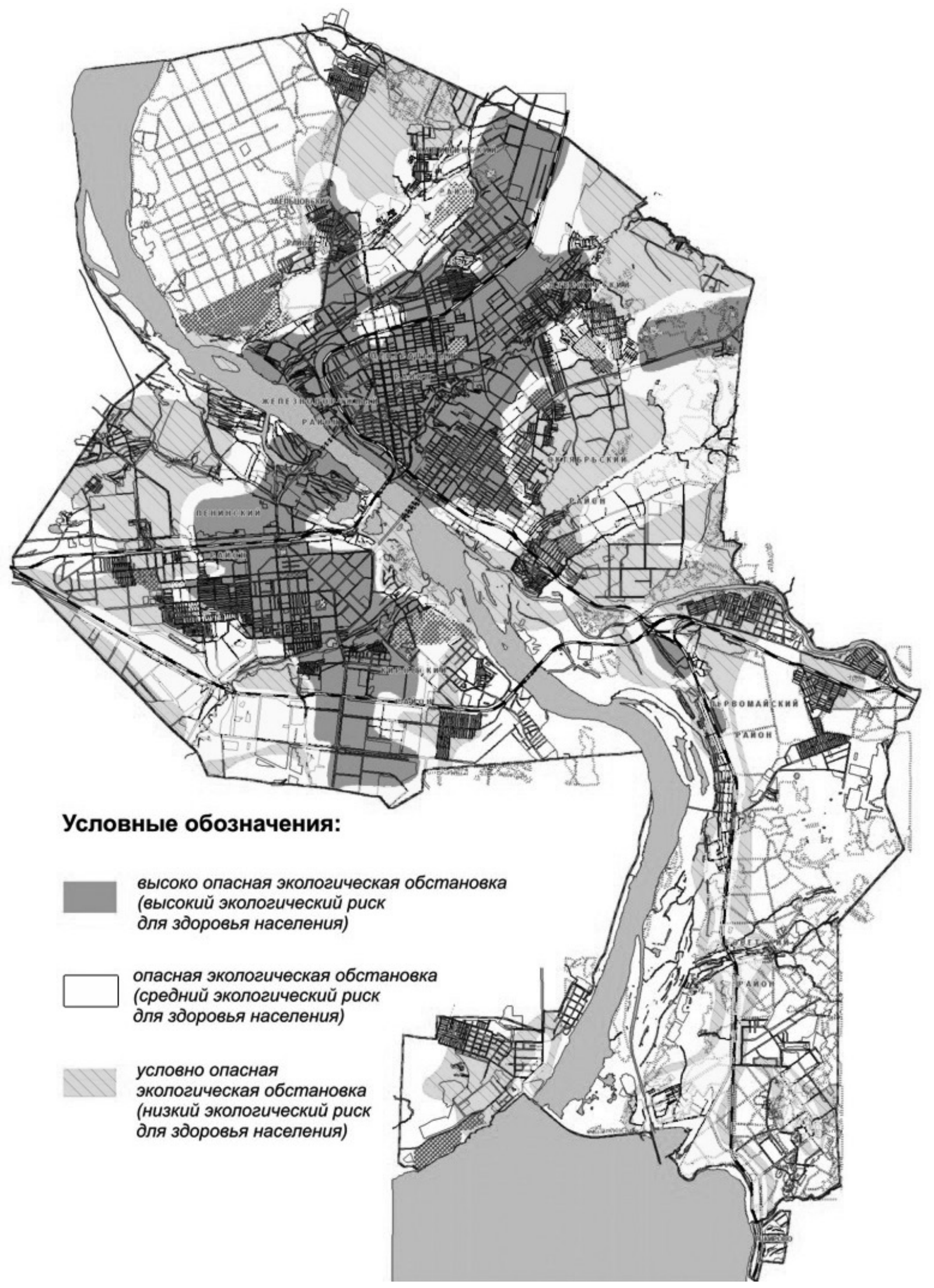

Рис. 1. Интегральная экологическая карта г. Новосибирска 
сов 3В которой превышает 8 тыс. тонн в год. В атмосферу города «поставляются» газы (оксиды азота, углекислый, угарный), сажа и другие вредные для здоровья вещества. Направление и сила ветра таковы, что зона приземной концентрации ЗВ охватывает около половины жилых кварталов Калининского района г. Новосибирска. На первом этапе контроллинга целесообразно, исходя из надлежащим образом сформированных исходных данных, максимально правдоподобно выполнить построение границ зон, в которых превышены ПДК отдельных типов ЗВ. На следующем этапе производится коррекция полученных результатов путем проведения натурных измерений.

Сформированная экологическая карта района является базой для процессов проектирования, производства, ввода в эксплуатацию технологий, устройств, снижающих (в идеальном варианте - ликвидирующих) распространение 3В в атмосферном воздухе. Задача экологического фонда «Зеленый стандарт» не только обратить внимание общественности, управляющих и производственных структур, но и аргументированно ускорить реальную экологическую работу.

Расчетные алгоритмы основаны на методиках, регламентированных приказом Минприроды России от 06.06.2017 г. №273 [1]. Ветровые нагрузки варьировались по направлению и скорости. Точечными источниками выбросов 3В ТЭЦ-4 являются две трубы высотой $H=60$ м, диаметры устья которых равны 5,2 м. Расстояние между ними составляет 100 м. Линия, соединяющая оси рассматриваемых труб, параллельна направлению «север-юг». Масса выбросов принята 8107,642 тонн/год, что составляет $M=0,261$ кг/с. Разница температур на выходе из устья труб $\Delta T=200^{\circ} \mathrm{C}$. Выбраны расчетные направления ветра: «восток-запад», «север-юг», «северо-запад - юго-восток», «северо-восток - юго-запад». Определено значение максимальной приземной разовой концентрации $C_{m}$ загрязняющих веществ при выбросе газовоздушной смеси из одиночного источника с круглым устьем при опасной скорости ветра $U_{m}(\mathrm{~m} / \mathrm{c})$ на расстоянии $X_{m}$ :

$$
C_{m}=A M F m n \eta\left(H^{2}(Q \Delta T)^{0,333}\right)^{(-1)} .
$$

Параметр, характеризующий свойства точечного источника выброса:

$$
v_{m}=0,65\left(Q \Delta T H^{(-1)}\right)^{0,333}=5,8 .
$$

Безразмерные коэффициенты, учитывающие условия выброса из устья источника:

$$
\begin{gathered}
n=3,13+2,13\left(v_{m}\right)+0,532\left(v_{m}\right)^{2}=2,01, \\
m=0,67+0,1 f^{(05)}+0,34 f^{0,333}=0,68,
\end{gathered}
$$

где $f=1000\left(D\left(Q S^{(-1)}\right)^{2}\right)\left(H^{2} \Delta T\right)^{(-1)}=0,000144$.

Тогда $C_{m}=1,223$ (мг/куб. м).

Расстояние от точечного источника выброса, на котором приземная концентрация загрязняющего вещества при неблагоприятных метеорологических условиях достигает максимального значения $C_{m}$, равно

$$
X_{m}=0,25(5-F) d H,
$$

где безразмерный коэффициент:

$$
\begin{gathered}
d=4,95 v_{m}\left(1+0,28 f^{0,333}\right)=28,71, \\
X_{m}=1723(\mathrm{M}) .
\end{gathered}
$$

Опасная скорость ветра на стандартном уровне флюгера (10 м от уровня земли), при которой достигается наибольшая приземная концентрация загрязняющего вещества, равна $U_{m}=6,24(\mathrm{м} / \mathrm{c})$. Скорости ветра в расчетах приняты $0,5,1,0,2,0$ от величины наиболее опасной скорости. При опасной скорости ветра приземная концентрация загрязняющего вещества в атмосферном воздухе на оси факела от точечного источника: $C=C_{m} s_{1}$ (мг/куб.м), где $s_{1}-$ безразмерный коэффициент, определяемый в зависимости от величины относительного расстояния между данной точкой и источником загрязняющего вещества:

при $\left(X / X_{m}\right)<1$ :

$$
\begin{gathered}
s_{1}=3\left(X / X_{m}\right)^{4}-8\left(X / X_{m}\right)^{3}+6\left(X / X_{m}\right)^{2}, \\
\text { при } 1<\left(X / X_{m}\right)^{<}<8: \\
\left.s_{1}=1,13\left(1+X / X_{m}\right)^{2}\right)^{(-1),}
\end{gathered}
$$

при $8<\left(X / X_{m}\right)<100$ :

$$
s_{1}=\left(120+3,556\left(X / X_{m}\right)^{2}-35,2\left(X / X_{m}\right)\right)^{(-1)} \text {. }
$$

Приземная концентрация загрязняющего вещества в атмосферном воздухе в направлении, перпендикулярном (координата «у») 
к оси факела выброса, учитывается соответствующим коэффициентом:

$$
s_{2}=\left(1+5(t)+12,8(t)^{2}+17(t)^{3}+45,1(t)^{4}\right)(t),
$$

где $(t)=U y^{2} X^{(-2)}, U-$ расчетная скорость ветра.

Алгоритм вычислений основан на конечно-разностной аппроксимации исходных соотношений. Математической моделью точечного источника является функциональный массив размером $43 \times 43$ элемента, значения которого вычисляются в рамках двойного цикла. Суперпозиция двух массивов с учетом смещения точечных источников друг относительно друга моделирует область приземной концентрации ЗВ. Для наглядности геометрический образ поверхности концентрации ЗВ представлен в виде системы концентрических замкнутых линий (линии уровня равной приземной концентрации 3В), нанесенных на карту района. Расчетные значения концентраций выражены в долях ПДК ЗВ. При направлении ветра «восток-запад» наибольшее значение превышает нормативное в три раза. Выполнен расчет границ области приземной концентрации 3В от 0,5 ПДК включительно для наиболее опасного значения скорости ветра. При удвоении значения скорости ветра область распространения ЗВ увеличивается в 1,32 раза, концентрация уменьшается в 0,75 раза. При половинной скорости ветра от наиболее опасного значения область уве- личивается в 1,26 раза, концентрация составляет 0,585 от наиболее опасного значения.

К западу от ТЭЦ-4 расположены жилые кварталы Юбилейного жилого массива. В направлении «восток» от ТЭЦ-4 расположена взлетно-посадочная полоса завода им. Чкалова, далее - дачные общества. Продольный размер области приземной концентрации 3В не превышает 2 км.

Рассмотренный расчетный случай совпадает с результатами ранее проведенных измерений зон приземной концентрации ЗВ в жилых кварталах Калининского района по методикам, утвержденным Госкомгидрометом 04.08.1986 г. №192 (ОНД-86 ГОСКОМГИДРОМЕТ).

Исходные данные направлений «северозапад» и «юго-восток» аналогичны рассмотренным выше. При формировании математической модели изменены координаты точечных источников. В результате вычислений построены изолинии равной приземной концентрации ЗВ в направлении «северо-запад». В направлении «юго-восток» сценарий образования областей приземной концентрации ЗВ симметричен направлению «северо-запад». Максимальное значение приземной концентрации ЗВ оказалось больше ПДК в 4,5 раза, т.к. произошло уменьшение расстояния между осями точечных источников в расчетном направлении ветра. Размер области приземной концентрации ЗВ увеличивается вдоль оси факела в 1,32 раза при удвоении ветровых нагрузок. Уменьшение концентрации в 0,75 раза су-

Таблица 1

Суммарные валовые выбросы загрязняющих веществ от ТЭЦ-4 в атмосферу

\begin{tabular}{|l|c|c|c|c|c|}
\hline \multirow{2}{*}{$\begin{array}{c}\text { Перечень } \\
\text { основных } \\
\text { ингредиентов }\end{array}$} & \multicolumn{5}{|c|}{ Выброшено в атмосферу, тонн } \\
\cline { 2 - 6 } & 2011 г. & 2012 г. & 2013 г. & 2014 г. & 2015 г. \\
\hline Зола углей & 1638,003 & 1784,902 & 1409,652 & 1586,824 & 1449,615 \\
\hline Мазутная зола & 0,013 & 0,007 & 0,000 & 0,000 & 0,000 \\
\hline Оксиды азота & 3424,768 & 3691,492 & 3700,743 & 3650,643 & 3760,792 \\
\hline Ангидрид сернистый & 2225,783 & 4884,766 & 4014,492 & 2881,747 & 2548,393 \\
\hline Углерод (сажа) & 238,602 & 0,000 & 0,000 & 118,870 & 136,343 \\
\hline Оксид углерода & 0,491 & 244,387 & 199,567 & 194,842 & 212,493 \\
\hline Бенз/а/пирен & 0,000 & 0,000 & 0,000 & 0,001 & 0,001 \\
\hline Прочие & 0,000 & 0,000 & 0,000 & 0,000 & 0,006 \\
\hline ИтОГО & $\mathbf{7 5 2 7 , 6 6 0}$ & $\mathbf{1 0 6 0 7 , 5 4 0}$ & $\mathbf{9 3 2 4 , 4 5 4}$ & $\mathbf{8 4 3 2 , 9 2 6}$ & $\mathbf{8 1 0 7 , 6 4 2}$ \\
\hline
\end{tabular}


щественно не уменьшает область приземной концентрации 3В, т.к. сближение точечных источников в расчетном направлении ветра увеличивает концентрацию более чем в 4 раза. Зоны приземной концентрации ЗВ находятся на территории жилых кварталов Калининского района. Данный расчетный случай демонстрирует значительное повышение концентрации оксида азота.

По данным таблицы 1 («Суммарные валовые выбросы загрязняющих веществ от ТЭЦ-4 в атмосферу»), диоксид азота составляет $46 \%$ от величины валового выброса 3В, следовательно, наибольшее значение его концентрации в 1,86 раза больше, чем в устье точечных источников ЗВ. Для сернистого ангидрида и золы углей аналогичные значения равны 1,24 и 0,71 соответственно.
В направлении «юго-восток» область приземной концентрации ЗВ «накрывает» парк культуры и отдыха «Сосновый бор», на территории которого расположен спортивный комплекс «Север». Справка: в спортивном комплексе «Север» проходят матчевые встречи местной команды «Локомотив» в рамках всероссийского чемпионата по волейболу. Игры сопровождаются присутствием тысяч болельщиков.

Далее рассмотрен случай направления ветра «север-юг». Результирующий двухмерный массив моделирует область приземной концентрации 3В, наибольшее значение которой увеличилась в пять раз относительно ПДК. Особенно опасно направление северного ветра, т.к. факел источников ЗВ ТЭЦ-4 направлен строго в жилые кварталы. Удвоение

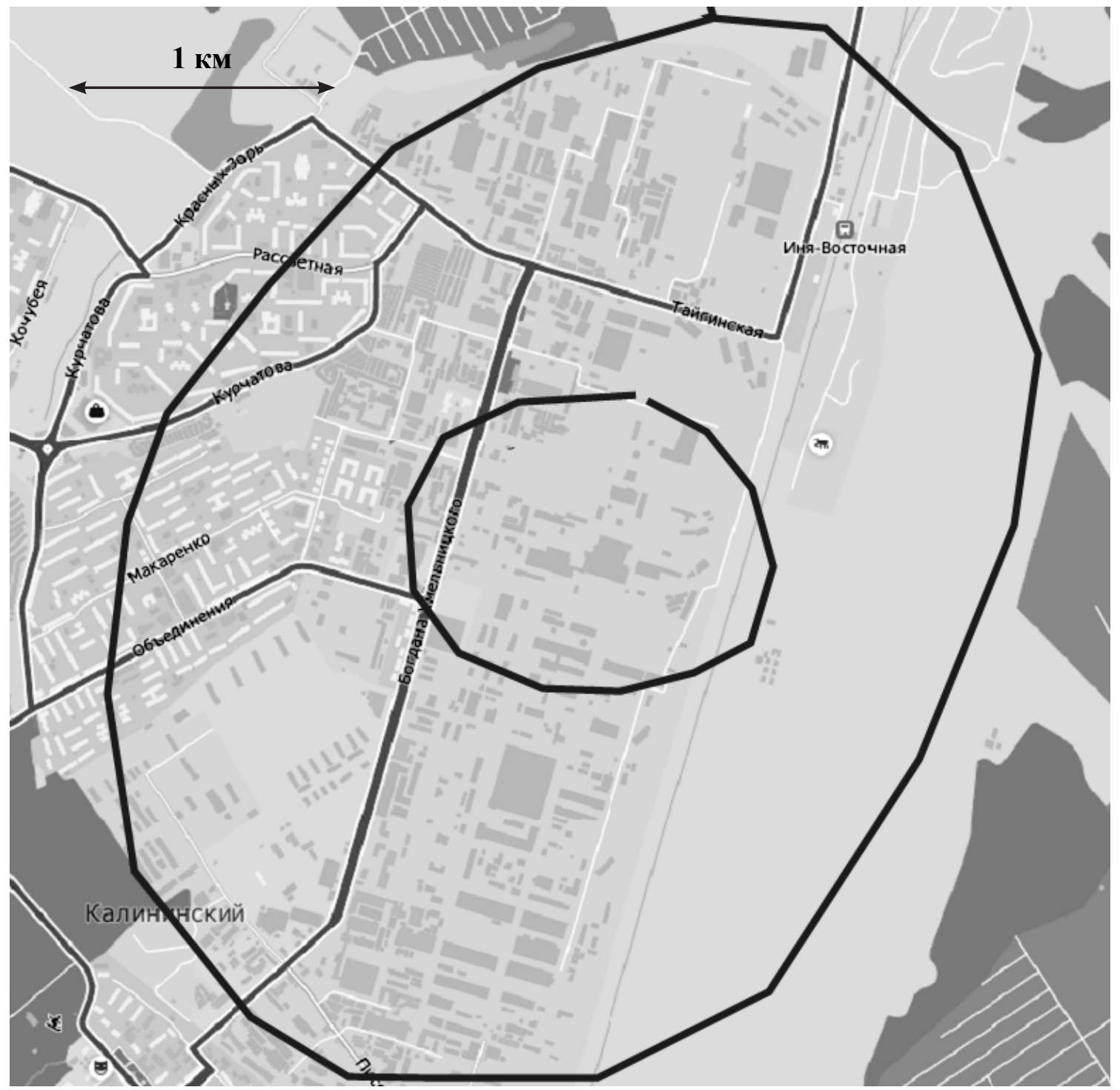

Рис. 2. Схема интегральной области повышенной приземной концентрации ЗВ от ТЭЦ-4 
силы ветра увеличивает продольный размер области приземной концентрации ЗВ в 1,32 раза при незначительном уменьшении этой области за счет диссипации ЗВ в атмосферном воздухе. Как показывают результаты контрольных измерений, наличие порывистых ветровых нагрузок (величина ветра до $20 \mathrm{~m} / \mathrm{c}$ ) расстояние распространения ЗВ от труб ТЭЦ4 достигает 5 километров. 3 км южнее ТЭЦ-4 расположен дворец спорта «Сибирь», в котором проходят матчевые встречи местного хоккейного клуба в рамках чемпионата Континентальной хоккейной лиги. Каждая игра значительное спортивное событие для всего города. Во дворце спорта «Сибирь» - аншлаг (несколько тысяч болельщиков, не считая скопления транспорта). В направлении «югсевер» расположена промышленная зона Калининского района.

Построение интегральной области повышенной приземной концентрации ЗВ выполнено на основании результатов, приведенных выше (рис. 2.). Учтено: при удвоенном значении ветра 3 В распространяются в 1,32 раза дальше, при половинной скорости ветра в 1,26 раза, приземная концентрация ЗВ уменьшается со значения ПДК до 0,75 ПДК для значения скорости ветра в 2 раза больше наиболее опасного значения (в данном случае 6,24 м/с). При половинной скорости ветра концентрация уменышается до 0,585 ПДК.

Интегральная область повышенной приземной концентрации 3В имеет кольцевой вид. Внутренняя граница - эллипсоидальная, наименьшая полуось равна 800 м, наибольшая - 1100 м. Внешняя граница вытянута с юга на север. Наибольшее расстояние от источника ЗВ составляет 2200 м, наименьшее 1600 м. Более половины площади области повышенной приземной концентрации 3В приходится на жилые кварталы Калининского района. Суммарные валовые выбросы загрязняющих веществ от ТЭЦ-4 в атмосферу в течение 2011-2015 гг. приведены в таблице 1. Сценарии распространения основных составляющих ЗВ ТЭЦ-4 практически совпадают.

Таким образом, определены зоны наибольшей приземной концентрации 3В: (оксида азота, угарного газа, сажи) от двух точеч- ных источников - труб ТЭЦ-4. Полученные данные дополняют результаты ранее проведенных измерений. Результаты представленной работы являются частью контроллинга экологическим фондом «Зеленый стандарт» деятельности предприятий топливно-энергетического комплекса (в данном случае ТЭЦ4 г. Новосибирска). Состояние атмосферного воздуха - важнейший фактор, определяющий экологические риски для здоровья населения. Достоверное исследование источника ЗВ позволяет наиболее эффективно реализовать защитные мероприятия. Применительно к ТЭЦ-4 таковыми являются:

- предварительная очистка каменных углей от органических и неорганических примесей, что позволяет существенно снизить концентрацию диоксида азота в выброcax ЗВ ТЭЦ-4;

- применение современных технологий сжигания существенно снижает концентрацию ЗВ в факеле выброса точечного источника;

- установка современных очистных устройств (пылеуловителей, уловителей газов), в том числе многоступенчатой очистки, изменение газодинамики продуктов сгорания взамен работающих очистных устройств устья труб ТЭЦ-4, несомненно, улучшает экологию атмосферного воздуха Калининского района в целом. Разработкой современных технологий очистки и сжигания топлив занимаются ученые института теплофизики им. Кутателадзе СО РАН.

\section{Литература}

1. Приказ Минприроды РФ от 06.06.2017 г. №273 «Об утверждении методов расчетов рассеивания выбросов вредных (загрязняющих) веществ в атмосферном воздухе».

2. Ларичкин В.В., Ларионов В.Г., жин И. А. Проблема переработки ТБО в Новосибирске в 2018 г. и возможные варианты решения. Журнал «Контроллинг». — 2018. №68 (2). - С. 28-35.

3. Охрана окружающей среды в Новосибирской области. Статистичекий сборник / Новосибирскстат. - Н., 2017. - 99 с. 


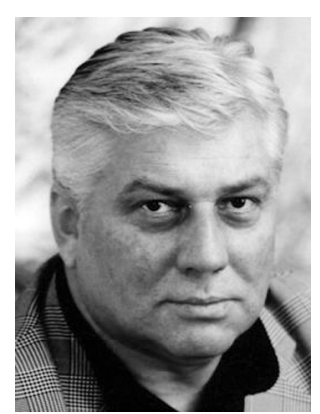

Ларионов Валерий Глебович - доктор экономических наук, профессор кафедры «Экономика и организация производства» Московского государственного технического университета им. Н.Э. Баумана.

Larionov Valery Glebovich - doctor of Economics, Professor of the Department of Economics and organization of production of Moscow state technical University named after N. E. Bauman.

105005, г. Москва, ул. 2-я Бауманская, 7

7 2nd Baumanskaya st., 105005, Moscow, Russia

Тел.: +7 (499) 267-00-49; e-mail: vallarionov@yandex.ru

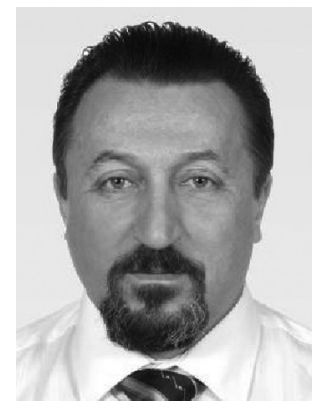

Ларичкин Владимир Викторович - доктор технических наук, профессор, заведующий кафедрой инженерных проблем экологии Новосибирского государственного технического университета.

Larichkin Vladimir Viktorovich - doctor of technical Sciences, Professor, head of the Department of engineering problems of ecology of Novosibirsk state technical University.

630073, г. Новосибирск, пр. К. Маркса, 20

20 K. Marksa av., 630073, Novosibirsk, Russia

Тел.: +7 (383) 346-50-31; e-mail: larichkin@corp.nstu.ru

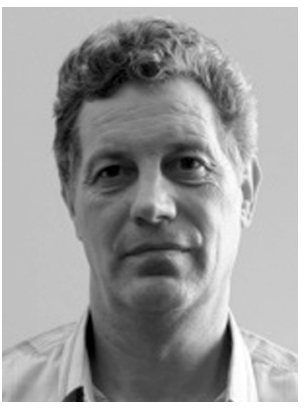

Сажин Игорь Александрович - кандидат технических наук, доцент, доцент кафедры технической теплофизики Новосибирского государственного технического университета.

Sazhin Igor Alexandrovich - candidate of technical Sciences, associate Professor, associate Professor of the Department of technical Thermophysics of Novosibirsk state technical University.

630073, г. Новосибирск, пр. К. Маркса, 20

20 K. Marksa av., 630073, Novosibirsk, Russia

Тел.: +7 (383) 346-06-42; e-mail: sajinia@ngs.ru 